\title{
SISTEM PENUNJANG KEPUTUSAN PEMILIHAN SISWA BERPRESTASI MENGGUNAKAN METODE WEIGHTED PRODUCT (STUDI KASUS :SMA MUHAMMADIYAH KECAMATAN KATINGAN TENGAH)
}

\author{
Widiatry ${ }^{a, 1, *}$, Nova Noor Kamala Sari ${ }^{b, 2}$, Arifatul Ananingtyas ${ }^{c, 3}$ \\ ${ }^{a}$ Universitas Palangka Raya, Jl. H. Timang \\ ${ }^{\mathrm{b}}$ Universitas Palangka Raya, Jl. H. Timang \\ ${ }^{\mathrm{c}}$ Universitas Palangka Raya, Jl. H. Timang \\ ${ }^{1}$ widiatry@it.upr.ac.id *; novanoorks@it.upr.ac.id; ${ }^{3}$ arifaningtyas2@ gmail.com; \\ * corresponding author
}

\section{ARTICLE INFO}

\section{Keywords}

Decision Support Systems

Selection of Excellent Students

Weighted Product

Waterfall Method

\begin{abstract}
The selection of outstanding students at SMA Muhammadiyah in Central Katingan District is conducted to appreciate the excellent students in order to be more motivated and active in learning activities. Building a website-based information system can apply the waterfall method and Weighted Product Method (WP) in its manufacture. The software development method used in making the support system for the students selection is the weighted product method (case study: SMA Muhammadiyah in Central Katingan District) . This waterfall method according to Sommerville (2011) includes 5 (five) stages namely requirement definition, system and software design, implementation and unit testing, integration and system settings, operation and maintenance. Application testing is conducted using the blackbox testing method, where the results of the test can see that the overall website-based decision support system is functions properly. However, it is expected that this application can continue to be developed and optimized for its use in the future, especially in terms of available features.
\end{abstract}

\section{Pendahuluan}

Pesatnya perkembangan peradaban manusia dewasa ini salah satunya diakibatkan oleh proses penyampaian informasi yang berjalan begitu lancar. Salah satu media penyebaran informasi yaitu melalui website.Pemilihan siswa berprestasi atau terbaik biasanya dilakukan di setiap sekolah dalam rangka mengevaluasi hasil belajar siswa-siswanya selama satu tahun.Dengan pemilihan siswa berprestasi atau terbaik ini untuk memacu siswa agar lebih giat dalam belajar dan aktif dalam kegiatandi sekolah ataupun di luar sekolah yang positif.

Pemilihan siswa berprestasi di SMA Muhammadiyah Kecamatan Katingan Tengah dilakukan untuk mengapresiasi siswa yang berprestasi agar lebih termotivasi untuk lebih berprestasi dan untuk siswa lainnya agar terpacu untuk lebih giat dan aktif dalam kegiatanbelajar.

Berdasarkan latar belakang yang sudah dijelaskan sebelumnya, maka terdapat rumusan masalah adalah Bagaimana merancang dan membangun Sistem Penunjang Keputusan Pemilihan Siswa Berprestasi Menggunakan Metode Weighted Product?

\subsection{Sistem pendukung keputusan(SPK)}

Sistem pendukung keputusan (SPK) adalah bagian dari sistem informasi berbasis komputer (termasuk sistem berbasis pengetahuan) yang dipakai untuk mendukung pengambilan keputusan dalam suatu organisasi atau perusahaan.Dapat juga dikatakan sebagai sistem komputer yang 
mengolah data menjadi informasi untuk mengambil keputusan dari masalah semi- terstruktur yang spesifik.

\subsection{Metode Weighted Product(WP)}

Metode Weighted Product (WP) adalah salah satu metode penyelesaian pada system pendukung keputusan.Metode ini mengevaluasi beberapa alternative terhadap sekumpulan atribuat atau kriteria, dimana setiap atribut saling tidak bergantung satu dengan yang lainnya.

Menurut Yoon (dalam buku Kusumadewi, 2006), metode weighted product menggunakan teknik perkalian untuk menghubungkan rating atribut, dimana rating tiap atribut harus dipangkatkan terlebih dahulu dengan bobot atribut yang bersangkutan.

Langkah-langkah penyelesaian WP sebagai berikut:

1. Menentukan kriteria-kriteria

Yaitu kriteria yang akan dijadikan acuan dalam pengambilan keputusan, yaitu Ci dan sifat dari masing-masing kriteria.

2. Memberikan nilai pada setiap alternative

Yaitu memasukkan nilai pada setiap alternatif pada setiap kriteria, dan Himpunan kriteria.

3. Melakukan normalisasi W Bobot Ternormalisasi = Bobot setiap kriterian / penjumlahan semua bobot kriteria.

Nilai dari total bobot harus memenuhi persamaan:

Langkah-langkah penyelesaian WP sebagai berikut:

4. Menentukan nilai vektor $\mathrm{S}$

$$
\sum_{j=1}^{n} w_{j}=1 .
$$

Dengan cara mengalikan seluruh kriteria bagi sebuah alternatif dengan bobot sebagai pangkat positif untuk kriteria benefit dan bobot berfungsi sebagai pangkat negatif pada kriteria cost.

Rumus untuk menghitung nilai preferensi untuk alternatif Ai, diberikan sebagai berikut:

$$
S_{i}=\prod_{j=1}^{n} x_{i j}{ }^{w_{j}}, \mathrm{i}=1,2, \ldots, \mathrm{m}
$$

5. Menentukan nilai vektor $\mathrm{V}$

Yaitu nilai yang akan digunakan untuk perangkingan.

Nilai preferensi relatif dari setiap alternatif dapat dihitung dengan rumus:

$$
V_{i}=\frac{\prod_{j=1}^{n} x_{i j}{ }^{w_{j}}}{\prod_{j=1}^{n}\left(X_{j}\right)^{w_{j}}} ; \quad \mathrm{i}=1,2, \ldots, \mathrm{m}
$$

Keterangan:

S: menyatakan preferensi alternatif yang

dianalogikan sebagai vektor $\mathrm{S}$

V menyatakan preferensi alternatif yang

dianalogikan sebagai vektor $\mathrm{V}$

$\mathrm{x}$ : menyatakan nilai kriteria

w : menyatakan bobot kriteria

i : menyatakan alternative

$\mathrm{j}$ : menyatakan kriteria

$\mathrm{n}$ : menyatakan banyaknya kriteria 
6. Merangking Nilai Vektor V

Sekaligus membuat kesimpulan sebagai tahap akhir.

\section{Metode Penelitian}

Untuk melakukan perancangan dan pembuatan Sistem Penunjang Keputusan (SPK) yang diinginkan perlu melakukan analisis agar system yang dibuat dapat sesuai seperti yang diinginkan. Adapun teknik pengumpulan data dalam pelaksanaan penelitian ini adalah sebagaiberikut :

a. Studi Pustaka

Mempelajari teori-teori yang ada pada buku-buku pengetahuan, skripsi, jurnal dari internet serta artikel-artikel lain yang berhubungan dengan permasalah yang ada.

b. Studi Lapangan

Melakukan observasi (pengamatan) langsung ke tempat lokasi objek penelitian yaitu SMA Muhammadiyah Katingan Tengah di jalan Minun Dehen No.04 Tumbang Samba Kabupaten Katingan.Pengamatan yang dilakukan dengan wawancara langsung dengan Kepala Sekolah SMA Muhammadiyah Katingan Tengah.

Metode pengembangan perangkat lunak yang digunakan yaitu metodologi Waterfall berdasarkan Sommervill (2011).dengan tahapan sebagai berikut.

\section{Requirements Definition}

Menganalisis kebutuhan yang diperlukan oleh admin user dalam pembuatan Sistem Penunjang Keputusan Pemilihan Siswa Berprestasi Menggunakan Metode Weighted Product (Studi Kasus : SMA Muhammadiyah Kecamatan Katingan Tengah) ini, guna mencari pilihan dan solusi fitur apa yang akan dirancang. Pada tahap analisis ini juga dilakukan pembuatan Flowchart.

2. System and SoftwareDesign

Pada tahap ini berguna untuk melakukan pendesainan interface web yang akan dibuat, tahap ini rancangan akan disesuaikan dengan kebutuhan pengguna. Pada tahap design ini juga dilakukan pembuatan Data Flow Diagram (DFD).

3. Implementation and Unit Testing

Penulisan program denganmenggunakan bahasa pemrograman PHP, dan MySQL sebagai perangkat untuk pembuatan databasenya.Perancangan perangkat lunak direalisasikan sebagai serangkaian program atau unit program.Pengujian unit melibatkan verifikasi bahwa setiap unit telah memenuhi spesifikasinya.

4. Integration and System Testing

Setelah didesain, dandilakukanpenulisan program, Website yang telah dibuat akan diimplementasikan. Website yang dibuat akan dilakukan pengujian terlebih dahulu, jika ada kesalahan, maka akan kembali ke metodologi sebelumnya yaitu pembuatan kode program. Metode testing yang digunakan pada pembuatan website ini adalah Metode Blackbox.

5. Operation and Maintenance

Mengoperasikan programdilingkungannya, sesuai dengan kebutuhan user dan melakukan maintenance atau pemeliharaan.Biasanya merupakan fase siklus yang paling lama (walaupun tidak seharusnya). Sistem di install dan di pakai. Pemeliharaan mencakup koreksi dan berbagai error yang tidak ditemukan pada tahap-tahap sebelumnya, perbaikan atas implementasi unit sistem dan pengembangan pelayanan sistem.Dalam merancang dan membangun SMA Muhammadiyah Kecamatan Katingan Tengah ntuk tahapan Maintenance (pemeliharaan) tidak dilakukan.

Apabila digambarkan dalam diagram, tahapan pada metodologi Waterfall ditunjukkan pada gambar 1 berikut. 


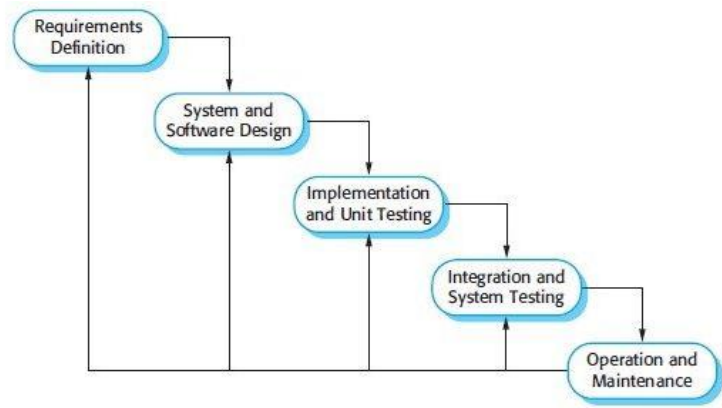

Gambar 1. Metode waterfall (Sommerville,2011)

\section{Hasil Dan Pembahasan}

Dari hasil analisis dan pengamatan, maka dapat ditentukan deskripsi sistem lama dan sistem baru pada SMA Muhammadiyah Kecamatan Katingan Tengah adalah sebagai berikut

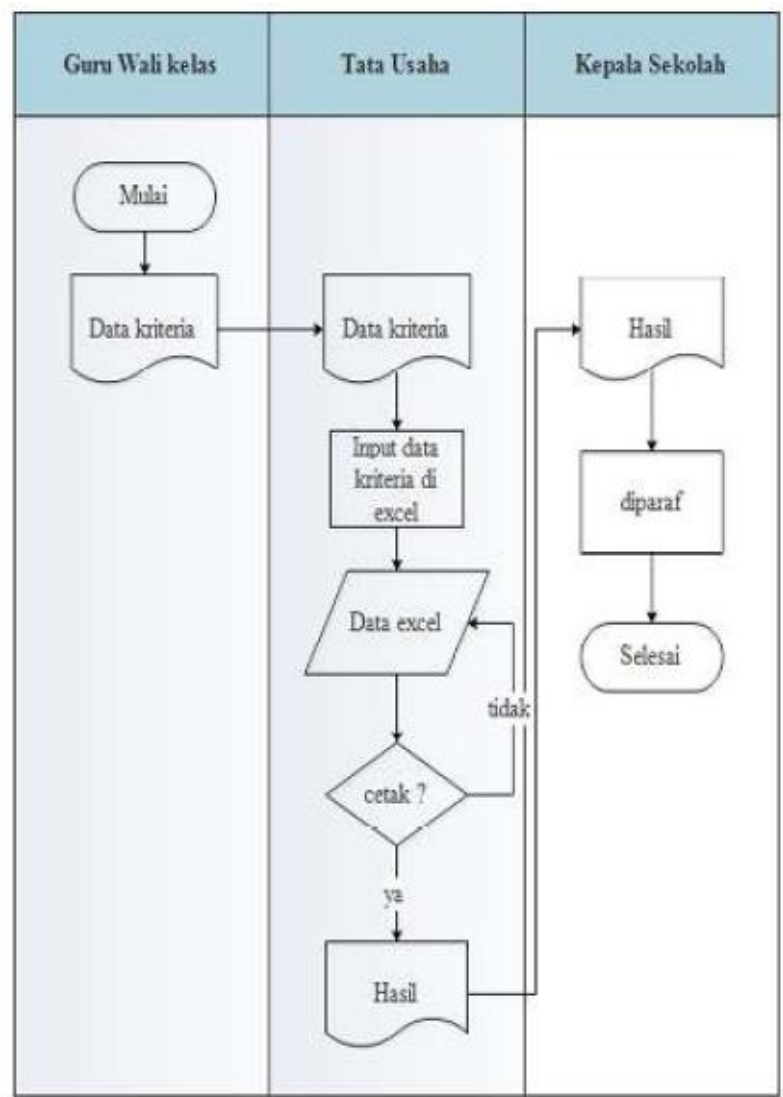

Gambar 2. Flowchart Sistem Lama 


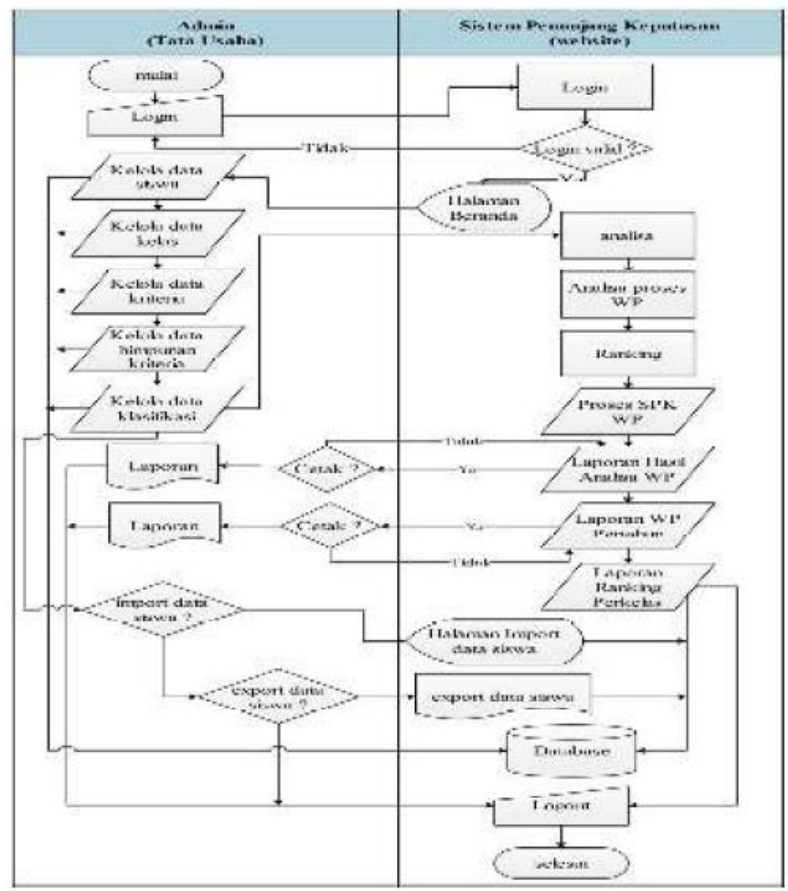

Gambar 3. Flowchart Sistem Baru

Penentuan pemilihan siswa berprestasi yang dilakukan dengan menggunakan metode Weighted Product.Flowchartdalam menentukan rekomendasi pemilihan siswa berprestasi dapat dilihat pada Gambar 4 dibawah ini.

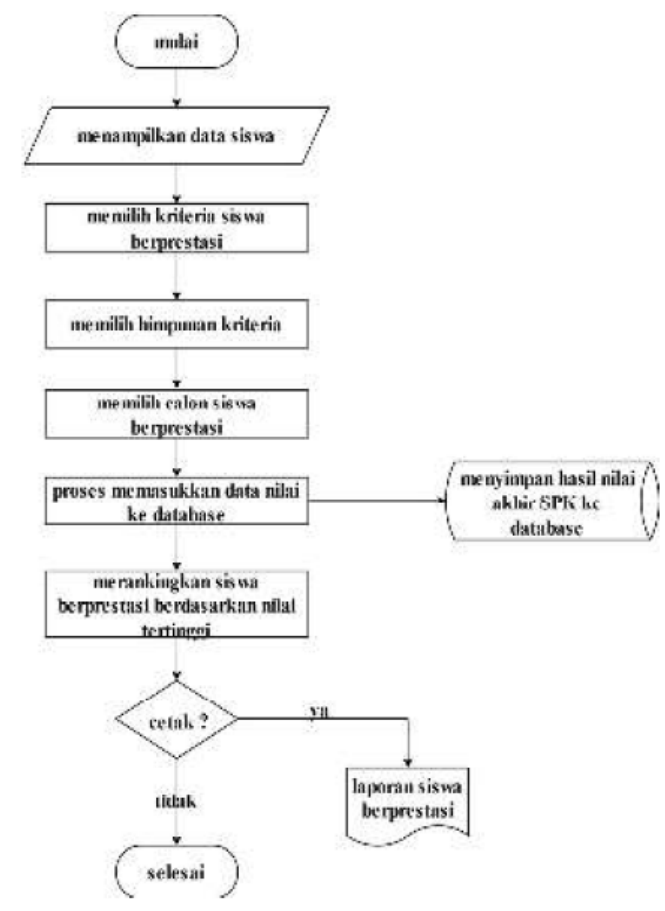

Gambar. 4. Flowchart Pemilihan SiswaBerprestasi 


\subsection{Perancangan Sistem}

Perancangan sistem dibagi menjadi pemodelan objek dengan menggunakan DFD (Data Flow Diagram) untuk menentukan skenario sistem dan aktivitas yang dilakukan pada sistem serta urutan interaksi yang terjadi pada sistem.

Diagram konteks digunakan untukmenggambarkan system pengolahan data pada proses Sistem Penunjang Keputusan PemilihanSiswa Berprestasi Menggunakan Metode Weighted Product secara garis besar atau keseluruhan. Diagram konteks ini dirancang memperhatikan masukan yang dibutuhkan oleh sistem dan keluaran yang dihasilkan oleh sistem

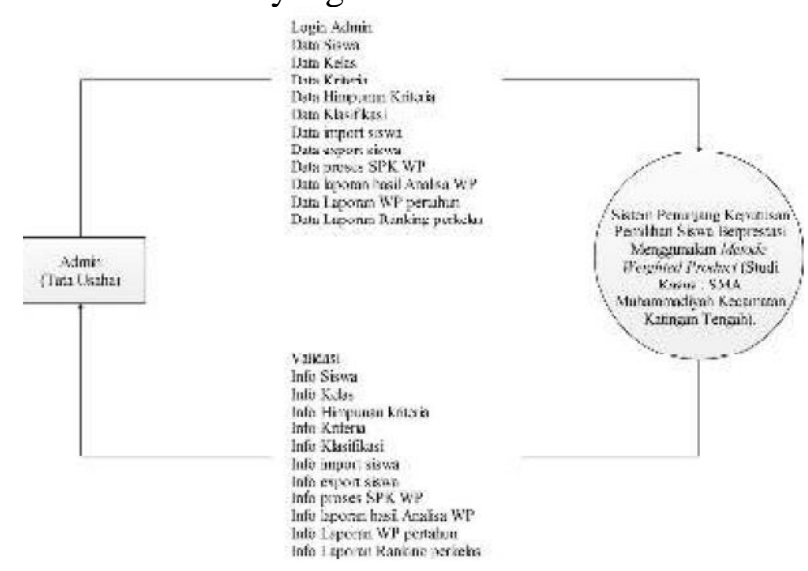

Gambar 5. Diagram Konteks

Data di dalam sistem disimpan dalam bentuk tabel-tabel yang saling berhubungan.Hubungan antar tabel tersebut digambarkan dalam bentuk Entity Relationship Diagram(ERD) seperti pada gambar 6.

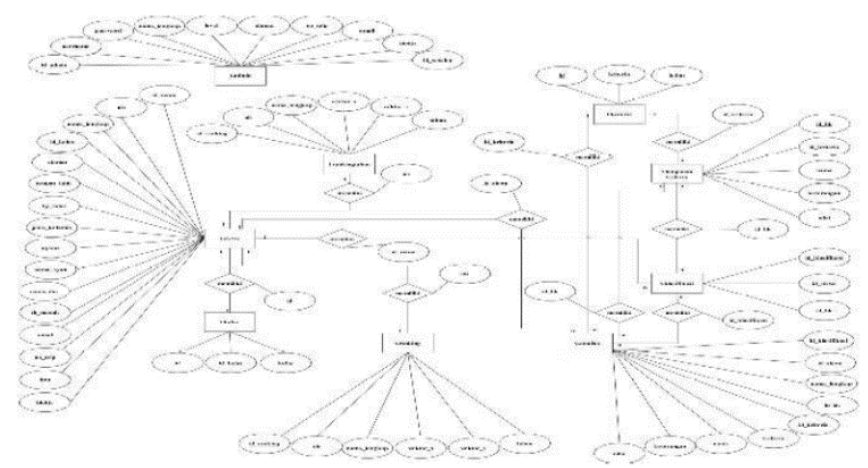

Gambar 6.Entity Relationship Diagram (ERD)

3.2 Implementasi

1. Tampilan Halaman Login

Implementasi Tampilan Login Sistem Penunjang Keputusan Pemilihan

Siswa Berprestasi dapat terlihat pada gambar 7 berikutini. 


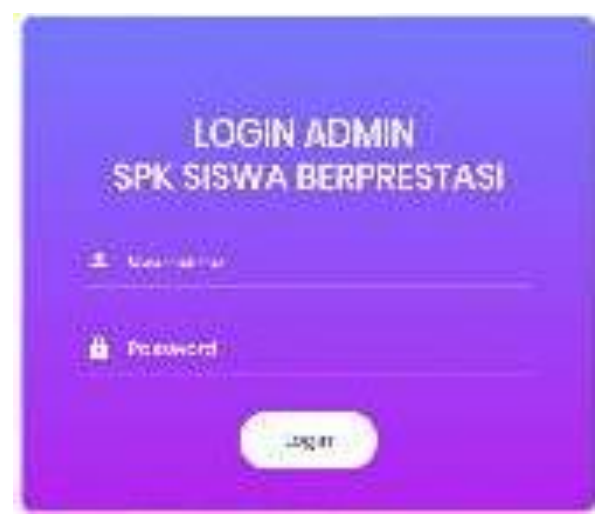

Gambar 7. Tampilan Halaman Login

2. Tampilan Halaman Dashboard

Implementasi Tampilan Dashboard Sistem Penunjang Keputusan Pemilihan Siswa Berprestasi dapat terlihat pada gambar 8 berikutini.

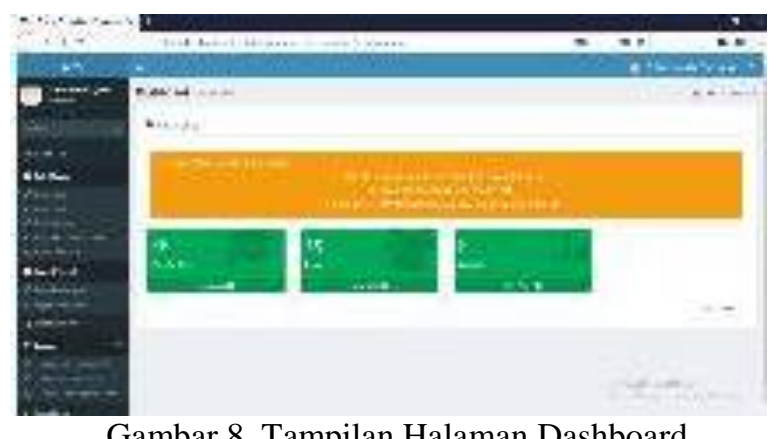

Gambar 8. Tampilan Halaman Dashboard

\section{Tampilan Halaman DataSiswa}

Implementasi Tampilan Data Siswa pada Sistem Penunjang Keputusan Pemilihan Siswa Berprestasi dapat terlihat pada gambar 9 berikut ini.

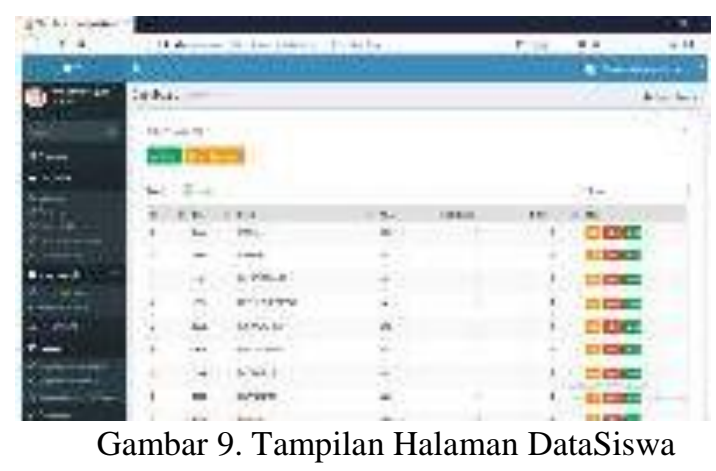

\section{Tampilan Halaman Proses SPKWP}

Implementasi Tampilan Proses SPK WPSistem Penunjang Keputusan Pemilihan Siswa Berprestasi dapat terlihat pada gambar 10 berikut ini. 


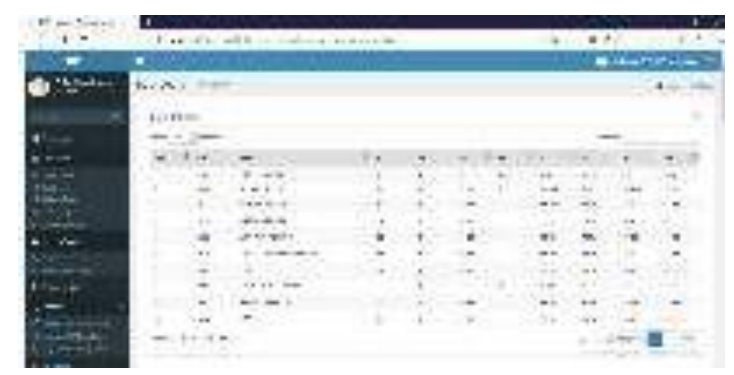

Gambar 10. Tampilan Halaman Proses SPK WP

\section{Kesimpulan}

Kesimpulan yang didapatkan dari Penelitian ini diawali dengan pengumpulan dan mempelajari literatur yang berkaitan dengan teori sistem penunjang keputusan Metode Weighted Product (WP). Tahapan metode WP yaitu menentukan kriteria-kriteria, memberikan nilai pada setiap alternatif, melakukan normaliasi $\mathrm{W}$, menghitung nilai vektor $\mathrm{S}$, menghitung nilai vektor $\mathrm{V}$ dan merangking nilai vektor $\mathrm{V}$.

Pada pembuatan sistem penunjang keputusan pemilihan siswa berprestasi menggunakan metode Weighted Product dilakukan tahapan awal yang dilakukan adalah dengan melakukan identifikasi permasalahan yang menjadi alasan dibuatnya sistem yang kemudian dilakukan pembuatan perumusan masalah.Selanjutnya analisa dan pengumpulan data dibagi menjadi dua yaitu studi pustaka dan studi lapangan melakukan observasi (pengamatan) langsung ke tempat lokasi objek penelitian dengan melakukan wawancara langsung dengan narasumber.Perancangan yang dilakukan yaitu perancangan basis data, perancangan sistem, dan terakhir perancangan antarmuka ( User Interface ). Kemudian implementasi sistem dalam bentuk program berbasis web menggunakan bahasa pemrograman PHP dan MySQL sebagai database. Proses yang terakhir melakukan pengujian sistem melalui antarmuka terhadap User dan program. Dimana aplikasi ini, memberikan daftar hasil penilaian ke dalam bentuk perankingan atau pengurutan dari nilai tertinggi sebagai bahan pertimbangan bagi sekolah dalam pengambilkeputusan.

\section{Daftar Pustaka}

[1] Ariyantini, Eka. 2012, Sejarah

Website,(Online:https://ekaariyantini.files.wordpress.com/2012/10/makalahwebsite.pdf,diakses 25 Mei2018).

[2] Darmawan, Deni dan Permana, Deden Hendra. 2013. Desain dan Pemrograman Website. Bandung : PT. Remaja Rosdakarya Offset.

[3] Hasan, 2014, Download Materi, Ebook, Modul Decision Support System (DSS) SPK.(Online:http://hasansundanisty.blogspot.co.id/2014/03/download-materi-ebook-moduldecision.html,diakses 25 Mei 2018).

[4] Jogiyanto,2005,Analisis dan Desain Sistem Informasi, Yogyakarta : PenerbitANDI.

[5] Sutedjo,Budidan Michael,Algoritma dan Teknik Pemrograman, Yogyakarta:Penerbit ANDI.

[6] Rachmat, Antonius, 2010,Algoritma dan Pemrograman dangan Bahasa C - Konsep, Teori \& Implementasi, Yogyakarta : Penerbit ANDI.

[7] Sari, Dewita, 2014, Pengetahuan Dasar ER Diagram (Diagram Relasi 
Entitas).(Online:https://pccontrol.wordpress.com/2014/02/14/pengetahuan-dasar-er-diagram-diagramrelasi-entitas/, diakses 25 Mei 2018).

[8] Simarmata, Janner, 2010, Rekayasa Perangkat Lunak. Yogyakarta : Penerbit ANDI.

[9] Suja, Imam, 2005, Pemrograman SQL dan Database Server MySQL. Yogyakarta : Penerbit ANDI.

[10] Suwirno, 2008, Pemanfaatan Efektivitas EDR J.Martin Dengan Chen.(Online: http://suwirno.blogspot.co.id/2008/04/pemanfaatan-efektivitas-erd-jmartin.html, diakses 25 Mei 2018).

[11] Syafrianto, Andri , 2017. Metode Weighted Product(WP),(Online:,http://www.gatewan.com/2017/03/metode-weighted-product-wp.html, diakses 25 Mei 2018).

[12] Tim LITBANG MADCOMS Madiun, 2009, Menguasai XHTML, CSS, PHP \& MySQLMelalui Dreamweaver, Yogyakarta : Penerbit ANDI. 